Egypt. Acad. J. biolog. Sci., 1 (1): 1- 9 (2009)

Email: egyptianacademic@yahoo.com

Received: 2/8/2009
E. Medical Entom. \& Parasitology

ISSN: 2090 - 0783

www.eajbs.eg.net

\title{
Effect of extrinsic incubation temperature on borrelial infection in various organs of Ornithodoros (O.) savignyi
}

\author{
Nadia Helmy ${ }^{1}$; Nawal M. Shanbaky ${ }^{1}$; Adel Abd Elmohsen ${ }^{2}$ and \\ Amira E. Abd-ElHamid ${ }^{1}$ \\ 1- Department of Entomology, Faculty of Science, Ain-Shams University \\ 2- Research and Training Center on Vectors of Diseases, Ain-Shams University
}

\begin{abstract}
Dissemination levels of Borrelia sp. isolated from a natural population of Ornithodoros savignyi in Egypt were assessed in various organs of the infected female tick reared at three different temperatures. Results of the present investigation showed that the extrinsic incubation temperature at which the infected tick was reared (EI) was crucial in affecting borrelial dissemination levels in different organs including gut, salivary glands, coxal organ, ovaries and hemolymph. The increase of EI from $17^{\circ} \mathrm{C}$ to $27^{\circ} \mathrm{C}$ and $37^{\circ} \mathrm{C}$ increased the infection rates (IRs) and mean number (no.).) of spirochetes localized in different organs. Also, it enhanced the appearance, prolonged persistence and delayed disappearance of spirochetes in most of the organs tested throughout the period of study ( 90 days after infective meal).
\end{abstract}

\section{INTRODUCTION}

The temperature at which the infected tick has been reared may influence the tick competence as a vector of disease and modify the course of infection with pathogens (Injeyan et al., 1971; Young et al., 1979; Young and Leitch, 1981; Dalgliesh and Stewart, 1982).

Few studies have shown that the extrinsic incubation temperature (EI) affects survival growth and transmission of lyme disease spirochete, Borrelia burgdorferi, and hence the competence of its ixodid tick vector (Shih et al., 1995). Infection with $B$. burgdorferi was reduced and undetectable in the gut of Ixodes scapularis nymphs kept at $33^{\circ} \mathrm{C}$ and $37^{\circ} \mathrm{C}$, respectively, as compared to moderate temperature at $27^{\circ} \mathrm{C}$. Furthermore, Barbour (1984) found that lyme disease spirochete $B$. burgdorferi did not grow when cultured in BSK II medium at temperature in excess of $37^{\circ} \mathrm{C}$. Also, Reisinger (1996) demonstrated that growth of two strains of $B$. burgdorferi was impaired when cultured at $37^{\circ} \mathrm{C}$ and inhibited at $39^{\circ} \mathrm{C}$ and $40^{\circ} \mathrm{C}$.

In argasid ticks, no studies have been done on the effect of EI or borrelial infection and competence of the vector tick since Hindl investigation (1911) on distribution of $B$. duttoni in organs of $O$. moubata kept at $21^{\circ} \mathrm{C}$ and $36^{\circ} \mathrm{C}$ where spirochetes were found only in organs of ticks kept at $36^{\circ} \mathrm{C}$.

Ornithodoros (O.) savignyi is one of seven ornithodorine tick species which had been recorded in Egypt (Hoogstraal \& Kaiser, 1958) and was found to be naturally infected and able to transmit a specific Borrelia sp. to mammals (Shanbaky and Helmy, 2000). In evaluating vector competence, knowledge about dissemination and intensity of borrelial infection in the tick organs is essential. Studies on infection of organs involved in transmission to mammals (salivary glands and coxal organs) and to tick offspring (ovaries) are of major importance.

The aim of the present study is to evaluate the effect of rearing $O$. (O.) savignyi at three constant temperatures $\left(17^{\circ} \mathrm{C}, 27^{\circ} \mathrm{C}\right.$ and $\left.37^{\circ} \mathrm{C}\right)$ on infection rates (IRs) with Borrelia sp. and mean numbers (no.) of the spirochetes in different organs and hemolymph of the adult female.

\section{MATERIALS AND METHODS}

Ticks and source:

Ornithodoros (O.) savignyi (Audouin), Argasidae, was collected from sand near cattle rearing places in Dahshore, Giza governorate, Egypt. The sand was sieved through paired large and small mesh metal sieves (Gaber et al. 1984). 


\section{Uninfected and infected tick colonies:}

Field collected uninfected adult ticks were used to start uninfected colonies and were maintained at $27 \pm 1^{\circ} \mathrm{C}, 75 \% \mathrm{RH}$ and $16 \mathrm{hrs} \mathrm{light/day.} \mathrm{Ticks} \mathrm{were} \mathrm{fed} \mathrm{on}$ hamster, Mesocricetus auratus as described by Helmy (2000).

Infected colonies started by feeding clean ticks on laboratory infected hamsters which had been fed upon by naturally infected $O$. savignyi. Infected colonies were kept at three different temperatures $\left(17^{\circ} \mathrm{C}, 27^{\circ} \mathrm{C}\right.$ and $\left.37^{\circ} \mathrm{C}\right)$.

Detection of spirochetes in ticks and hamster:

Blood smears from tick and hamster (Helmy, 2000) were stained with Fontana stain (Conn et al., 1960) or with direct (Piesman et al., 1986) and indirect immunofluorescence technique (Lane and Manweiler, 1988), respectively.

For IDF antigen slides were prepared from spirochetes obtained from ticks and cultured in modified Kelly's medium (Barbour et al., 1983). The spirochetes were centrifuged at $9000 \mathrm{xg}$ for $20 \mathrm{~min}$. at $22^{\circ} \mathrm{C}$ and the spirochete pellet was washed six times in sterile pbs adjusted to $\mathrm{pH} 7.4$ and supplemented with $5 \mathrm{mM}$ magnesium chloride. The spirochete pellet was diluted in pbs and applied to wells in scored slides for IDF test. The slides were incubated at $37^{\circ} \mathrm{C}$ until dry and stored at $-70^{\circ} \mathrm{C}$ until used.

Spirochetes localization and number in tick organs:

Newly moulted uninfected females of $O$. savignyi were fed on infected hamsters. Counts were made in hemolymph $(1 \mu 1)$ and different organs of each of 10 females daily for 10 days and then every 5 days for 60 days after feeding (daf) and then every 10 days till 90 daf. Hemolymph was collected and blood smears were prepared on slides. Gut, salivary glands, coxal organ and ovaries were dissected in a saline solution, squashed on slides, stained and examined microscopically and spirochete number in each organ was counted in ticks at each tested temperature.

The percentage of infection (IR) and mean number (no.).) of spirochete in hemolymph and each organ was calculated. Data were analyzed using Chi- square test with the aid of Statistical Package for Social Science (SPSS) version 8.0 for Windows.

\section{RESULTS AND DISCUSSION}

The spirochetes infection rate (IR) and mean number (no.) in various organs and HL of the female $O$. savignyi are illustrated in Figures 1-5.

\section{Localization of Borrelia sp. in the gut:}

Spirochetes were observed in the gut contents of all adult females of $O$. savignyi on the first daf on hamster infected with Borrelia sp. Spirochetes persisted in the gut lumen for 80 and 90 daf of ticks kept at $17^{\circ} \mathrm{C}$ and $27^{\circ} \mathrm{C}$ or $37^{\circ} \mathrm{C}$, respectively (Figs. $1 \mathrm{a} \& \mathrm{~b}$ ). During these periods, (IRs) and (no.) of spirochetes per gut were relatively high at the beginning (IR = 90-100\%; no. $=96 \pm 10.02$, $103.9 \pm 14.3$ and $111.4 \pm 11.55$, respectively) and gradually decreased $(\mathrm{P}<0.05)$ in subsequent days after feeding, starting on day $8(\mathrm{IR}=80 \%$, no. $=29.7 \pm 5.29), 25(\mathrm{IR}$ $=80 \%$, no. $=39.1 \pm 7.39)$ and $35(\mathrm{IR}=$ $80 \%$, no. $=33 \pm 6.15$ ), at the three tested temperatures, respectively, to reach minima $(\mathrm{IR}=10 \%, \quad \mathrm{n} \underline{\underline{0}} .=0.4 \pm 0.39$, $0.3 \pm 0.29$ and $1 \pm 0.67)$ at the end of their persistence period.

The present findings conform to those reported by Burgdorfer (1951), Teravsky (1959) and Nikita (1964 \& $1965)$ where numbers of the spirochete $B$. duttoni, $B$. sogidiana and $B$. anserim greatly decreased in the gut lumen few days after infection in O. moubata, $O$. papillipes (tholozani) and Argas persicus, respectively, until disappeared. Migration of the spirochetes from the gut to the hemolymph may contribute to the observed drop in no. of spirochetes in the gut. Furthermore, Balashov (1972) suggested that later disappearance of spirochetes from gut lumen in ticks is probably associated with the unfavorable changes as ingested blood is gradually digested.

In accordance with the present findings are those of Helmy (2000) where Borrelia sp. IRs in field collected nymphs and adults of $O$. savignyi were high in summer months and low in winter months during which the highest and lowest temperatures were recorded, respectively. 


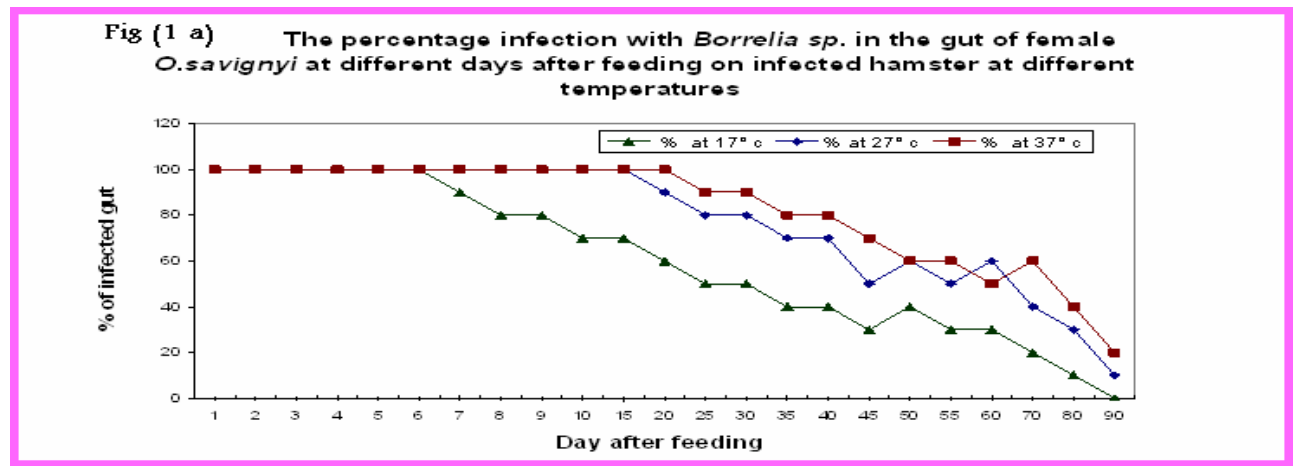

Fig ( $1 \mathrm{~b}$ ) The mean number of Borrelia sp. in the gut of female O.savignyi at different days after feeding on infected hamster at different temperatures.
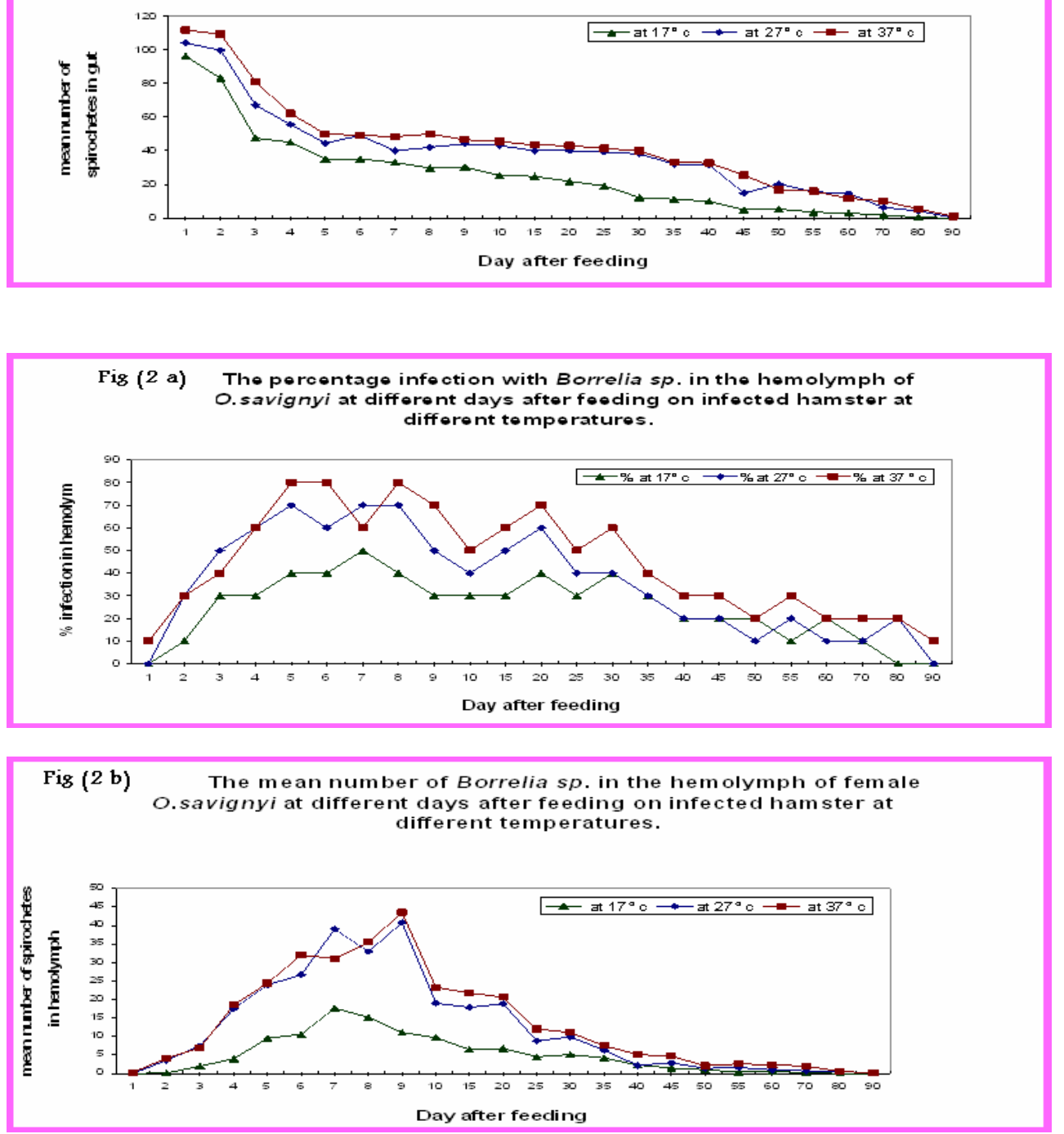

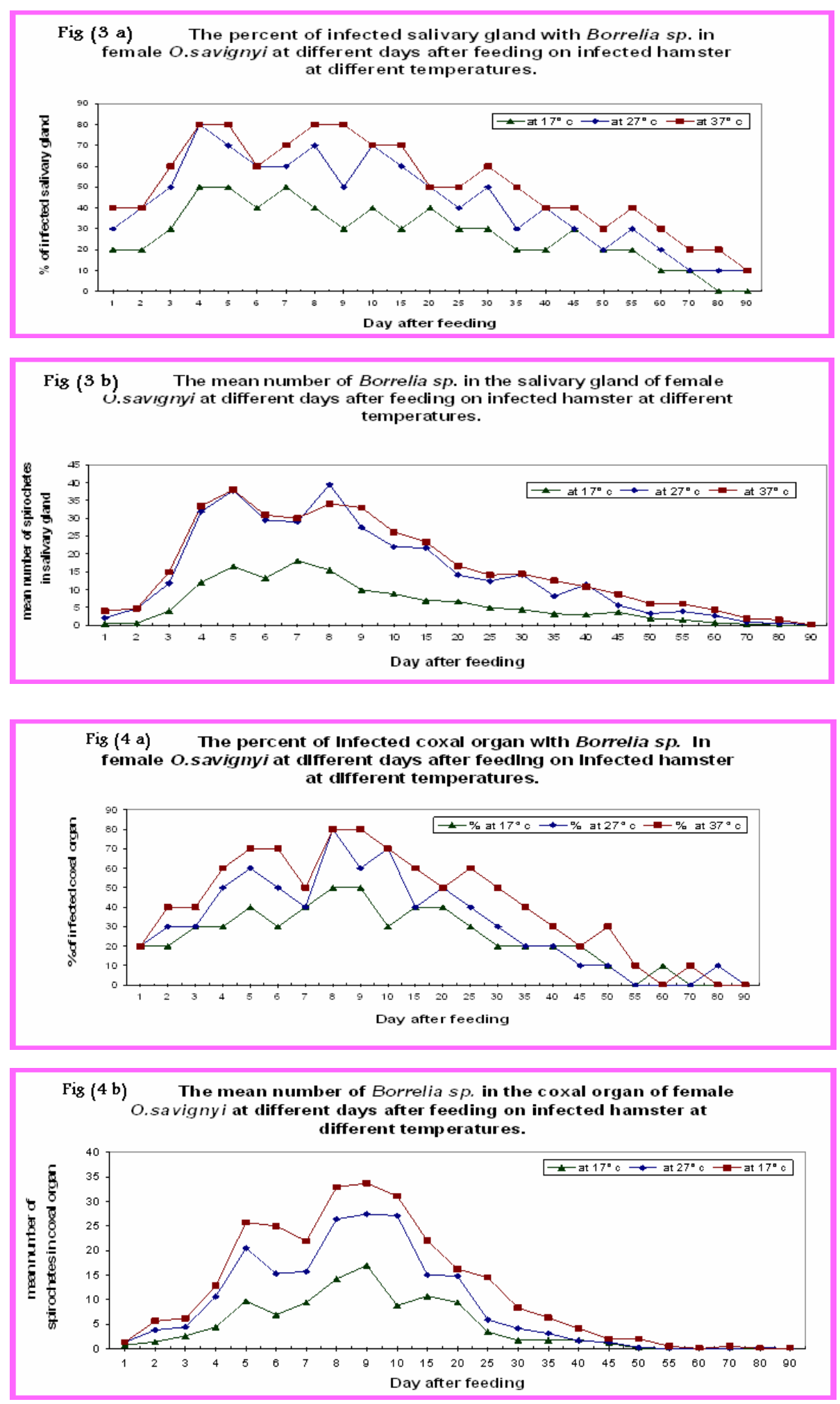

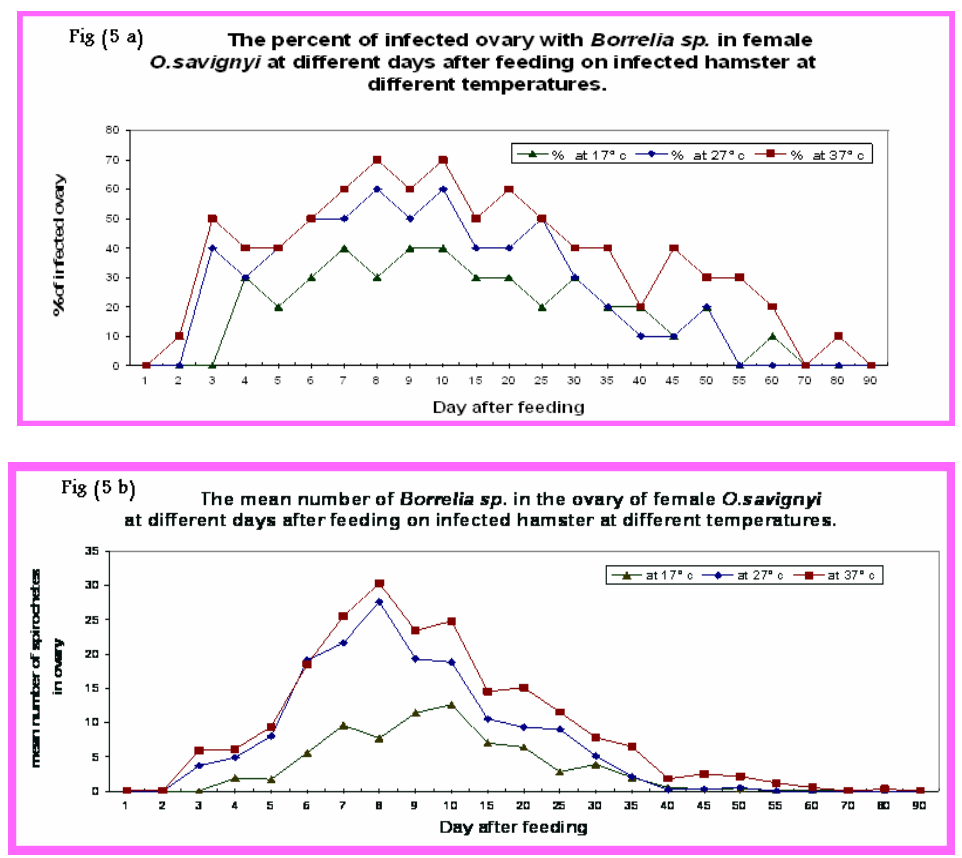

The relatively high temperature, among other factors prevailed in summer might have contributed to the increased IR's reported in the aforementioned study. Temperature is one environmental factor known to affect persistence of spirochetal infection inside the tick. Shih et al. (1995) demonstrated that the persistence of spirochetal infection of the lyme disease $B$. burgdorferi in the gut of the nymphal deer tick, Ixodes dammini was reduced or became undetectable by incubation of the ticks at temperatures higher than $27^{\circ} \mathrm{C}$ $\left(33^{\circ} \mathrm{C}\right.$ and $37^{\circ} \mathrm{C}$, respectively), for longer than two weeks. Although findings of the present study agreed with those of Shih et al. (1995) in the existence of an effect of EI on the level of borrelial infection inside the tick, our data pointed to a general increase of IR and no. of spirochetes and prolongation of persistence of infection inside the gut of the infected $O$. savignyi by increasing EI of the tick from $17^{\circ} \mathrm{C}$ to $27^{\circ} \mathrm{C}$ or $37^{\circ} \mathrm{C}$ but not from $27^{\circ} \mathrm{C}$ to $37^{\circ} \mathrm{C}$. This difference might be attributed to probable biological and physiological differences of borreliae and tick species used in both studies.

\section{Localization of Borrelia sp. in hemolymph:}

In hemolymph of adult female $O$. savignyi, spirochetes were detected in the second and first daf of the tick and persisted for 70,80 and 90 daf at $17^{\circ} \mathrm{C}$, $27^{\circ} \mathrm{C}$, and $37^{\circ} \mathrm{C}$, respectively (Fig. 2 a \& b). During these periods, IR's and no. of spirochetes in the hemolymph showed an initial period of increase $(\mathrm{P}<0.05)$ in their levels to reach maxima on 7-8 daf (IR = $40-50 \%$, no. $=15.2 \pm 7.14-17.7 \pm 8.87), 5-$ 9 daf $(50-70 \%$, no. $=23.9 \pm 6.61-$ $40.8 \pm 15.47$ ) and $5-9$ daf (IR $=70-80 \%$, no. $=24.4 \pm 4.91-43.5 \pm 10.80)$ at $17^{\circ} \mathrm{C}$, $27^{\circ} \mathrm{C}$ and $37^{\circ} \mathrm{C}$, respectively. This was followed by a gradual decrease $(\mathrm{P}<0.05)$ of the levels to reach minima (IR $=10,20$ $\& 10 \%$, no. $=0.2 \pm 0.19,0.7 \pm 0.52 \&$ $0.1 \pm 0.09 \quad$ at $\quad 17^{\circ} \mathrm{C}, \quad 27^{\circ} \mathrm{C} \quad \& \quad 37^{\circ} \mathrm{C}$, respectively) at the end of their persistence period.

It is well documented that borreliae as well as other pathogens ingested during tick feeding on infective blood penetrate the gut wall and enter hemolymph to be distributed to other organs (Balashov, 1972 \& Hoogstraal, 1985). In the present study, the initial increase of spirochete number in HL could be attributed to their migration from the gut to HL as was reported in other tick species (Gaber et al., 1984 \& Helmy et al., 1996). However, multiplication of Borrelia sp. in HL might have contributed to their increase. Hodzic et al. (2002) reported that feeding stimulates spirochetes multiplication and their number may increase markedly after tick feeding on either infected or uninfected 
host.Generally, IR of ticks with spirochetes in HL is dependent on the species of the vector and agent and also by the physiological state of the tick (Balashov, 1972). Hemolymph of argasid tick is known to be rich in important nutrients, fatty acids and amino acids which provide a favorable condition for multiplication of spirochetes (Burgdorfer et al., 1989). Furthermore, tick HL has been reported as a favorable medium which allows survival and intracellular multiplication of other pathogenic organisms such as rickettsiae (Balashov and Daiter, 1965) and piroplasm (Markov \& Abromov, 1958). The aforementioned investigations support the present suggestion that migration from the gut and multiplication in HL of Borrelia sp. may explain the initial increase of the IRs and no. of the spirochete in $\mathrm{Hl}$ during the first few days after the tick infective meal at the three tested temperatures in the present study.

\section{Localization of Borrelia sp. in salivary glands and coxal organ:}

Spirochetes were detected in salivary glands and coxal organ of female $O$. savignyi infected with $B$. sp. as early as the first daf at all temperatures tested (Fig. $3 \& 4$ ). Generally in each organ (salivary and coxal) there was a period of a gradual increase $(\mathrm{P}<0.05)$ of IR and no. of spirochetes per organ to reach maxima where the risk of transmission of $B$. $s p$. from the tick to host is anticipated to increase (Piesman et al., 2001). These maxima were reached in the salivary glands on 4-8 daf (IR $=40-50 \%$, no. $=$ $12+4.49-18.1+6.53), 4-15$ daf $($ IR $=60-$ $80 \%$, no. $=21.7 \pm 6.79-37.8 \pm 9.17)$ and $4-$ 15 daf ( $\mathrm{IR}=60-80 \%$, no. $=23.4+5.43-$ $38 \pm 7.31)$ at $17^{\circ} \mathrm{C}, \quad 27^{\circ} \mathrm{C} \quad \& \quad 37^{\circ} \mathrm{C}$, respectively. In coxal organ maximal infection levels were reached on 8-9 daf $(\mathrm{IR}=50 \%$, no. $=14.2 \pm 5.27-17 \pm 6.45), 8$ 10 daf $(\mathrm{IR}=60-80 \%$, no. $=26.4 \pm 7.13-$ $27.4+8.69$ ), and $8-10$ daf (IR $=70-80 \%$, no. $=31.1 \pm 7.41-33.7 \pm 6.76)$ at $17^{\circ} \mathrm{C}$, $27^{\circ} \mathrm{C} \& 37^{\circ} \mathrm{C}$, respectively. The increase of infection levels was followed by a period of a gradual decrease $(\mathrm{P}<0.05)$ of the spirochetal infection until disappeared from the salivary glands on 80 daf at $17^{\circ} \mathrm{C}$ or reached minima at the end of the persistence period in the gland (90 daf) at $27^{\circ} \mathrm{C}$ and $37^{\circ} \mathrm{C}$. Spirochetes nearly disappeared from coxal organs on 55-80 daf of the three tested temperatures.

The early appearance of spirochetes (first daf) in the salivary glands might be attributed to contamination of the gland during feeding on infective blood meal or dissemination from hemolymph. De-Silva and Fikrig (1995) demonstrated that the spirochete, $B$. burgdorferi had disseminated to the salivary glands in the majority of nymphs of Ixodes scapularis 36-48 hrs after attachment. Piesman et al. (2001) found that spirochete, $B$. burgdorferi in the tick salivary glands increased more than 17 fold from 1.2 per salivary gland pair before feeding to 20.8 at $72 \mathrm{hrs}$ post attachment. The period of the most rapid increase in number of spirochetes in the salivary glands occurred from 48 to $60 \mathrm{hrs}$ post attachment. This time period coincided with maximal increase of transmission risk during nymphal feeding. Furthermore, heavy infections with $B$. duttoni, B. sogidiana and B. anserina were observed in the salivary glands of $O$. moubata (Giegy, 1951), O. tholozani (Teravsky, 1959) and Argas persicus (Nikitina, 1965), respectively. Varma (1956) reported that the transmission of relapsing fever spirochetes by Ornithodoros ticks was mainly by inoculation of infective saliva and coxal fluid into the bite wound. In the present work, early appearance of spirochetes in the coxal organs of female $O$. savignyi can be correlated to the production of the coxal fluid which is discharged during feeding and shortly after detachment of the argasid tick species (Balashov, 1972).

Localization of Borrelia sp. in the ovary:

Spirochetes showed their first appearance in the ovary of female $O$. savignyi on the fourth, third and second daf on infected hamsters at $17^{\circ} \mathrm{C}, 27^{\circ} \mathrm{C}$, and $37^{\circ} \mathrm{C}$, respectively (Fig. $5 \mathrm{a} \&$ b). The initial appearance was followed by a gradual increase $(\mathrm{P}<0.05)$ of IR and no. of spirochetes in ovaries up to 10 daf at the three-tested temperatures (Fig. 5 a \& b). Maximal infection levels in ovaries reached on $7-10$ daf at $17^{\circ} \mathrm{C}$ (IR $=30-40 \%$, no. $=7.7 \pm 4.54-12.6 \pm 5.55)$, and on $6-10$ 
daf at $27^{\circ} \mathrm{C}(\mathrm{IR}=50-60 \%$, no. $=18.8+6.19$ $-27.6 \pm 8.50)$ and $37^{\circ} \mathrm{C}(\mathrm{IR}=50-70 \%$, no. $=18.5 \pm 6.7-30.3 \pm 7.41)$. Infection levels decreased $(\mathrm{P}<0.05)$ in subsequent days until spirochetes nearly disappeared on 55 , 55 and 70 daf at $17^{\circ} \mathrm{C}, 27^{\circ} \mathrm{C}$ and $37^{\circ} \mathrm{C}$, respectively.

Heavy infections of the reproductive organs of $O$. moubata with $B$. hispanica (Grun 1950) and B. duttoni (Giegy, 1951) and of Ixodes pacificus with B. burgdorferi (Burgdorfer, et al., 1989) were reported. Zhenqin (1998) stated that B. burgdorferi could be found intracellularly within ovaries of $I$. ricinus. We suggest that migration and penetration of spirochetes into ovaries and oocytes of the tick vector are prerequisites of transovarial transmission. Also, it could be considered as a physiological adaptation increasing the potential and competence of the tick as a reservoir and vector of a pathogen (Hoogstraal, 1985). Furthermore, localization of the spirochete in the ovaries may help in recognizing the specificity of the tick species as a vector of a certain B. species particularly in ornithodorine and some argasid ticks (Balashov, 1972 \& Hoogstraal, 1985). Experimental infection of some argasid (Diab \& Soliman, 1977 and Zaher et al., 1977) and of some ornithodorine (Gaber et al., 1984 and Shanbaky \& Helmy, 2000) tick species with borreliae species isolated from other tick vectors resulted in failure of localization of the spirochetes in the gonads and transovarial transmission in the unnatural recipients.

In general, there was no significant difference $(\mathrm{P}>0.05)$ between IR and no. of spirochetes in each organ of $O$. savignyi adult females kept at $27^{\circ} \mathrm{C}$ and $37^{\circ} \mathrm{C}$ at different daf. However, there was a significant increase $(\mathrm{P}<0.05)$ of infection levels in each organ of females kept at $27^{\circ} \mathrm{C}$ and $37^{\circ} \mathrm{C}$ than females kept at $17^{\circ} \mathrm{C}$ at different daf.

The results and discussion of the present study show that the appearance, persistence, IR and no. of the spirochete varied in the different organs examined which conform with other previous investigations (Varma, 1962; Balashov, 1972; Diab \& Soliman, 1977; Zaher et al., 1977, and Gaber et al., 1984). It was suggested (Burgdorfer, 1951), and experimentally demonstrated (Sarsian, 1959, and Grun \& Blatter, 1960) that chemotropic factors induce microorganisms to migrate and to localize in tick tissues.

The present work, showed that the increase of the extrinsic incubation temperature (EI) at which the female $O$. savignyi infected with Borrelia sp. was kept, crucially affected dissemination levels of the spirochete in organs of the tick vector. Increasing EI temperature from $17^{\circ} \mathrm{C}$ to $27^{\circ} \mathrm{C}$ or $37^{\circ} \mathrm{C}$ significantly increased the IR and no. of spirochetes in different organs. Also, it enhanced the initial appearance and prolonged persistence or delayed disappearance of spirochetes in most of the organs tested throughout the period of study (90 daf after infective meal).

\section{REFERENCES}

Balashov, Yu.S. (1972). Blood sucking ticks (Ixodidea) vectors of disease of man and animals. Miscell. Pub. Entomol. Soc. Am., 8(5): 161-376.

Balashov, Yu.S. and Daiter, A.B. (1965). Localization and dissemination of Rickettsia burneti in Ornithodoros papillips Bir. Doki. 16-17. Ezhegodn. Chten. Pamyati N.A. Kholod Kousky (3 April 1963-3 April 1969) P. 34-49.

Barbour, A.G. (1984). Isolation and cultivation of Lyme disease spirochetes. Yale J. Biol. Med., 57: 512-525.

Barbour, A.G.; Burgdorfer, W.; Hayes. S.F., Peter, O. and Aeschlimann, A. (1983): Isolation of a cultivation spirochete from Ixodes ricinus ticks of Switzerland. Curr. Microbiol., 8: 123-126.

Burgdorfer, W. (1951). Analyse des infections verlaufes bei $O$. moubata (Murray) under naturlichen Uebertrag. Ung Ven Spirochaeta duttoni. Act. Trop., 8: 193-262.

Burgdorfer, W.; Hayes, S.F. and Crowin, D. (1989). Path physiology of the Lyme disease spirochete, Borrelia burgdorferi in ixodid ticks. Rev. Infect. Dis., 11: 51442-51450.

Conn, H.J., Darrow, M.A. and Emmel, V.M. (1960). Staining procedure 
used by the biological stain commission. $2^{\text {ed. }}$ The Williams and Wilkins Company. Baltimore. 289 pp.

Dalgliesh, R.J. and Stewart, N.P. (1982). Some effects of time, temperature and feeding on infection rates with Babesia bovis and Babesia begemina in Boophilus microplus larvae. I.J.P., 12(4): 323-326.

De-Silva, A.M. and Fikrig, E. (1995). Growth and migration of Borrelia burgdorferi in Ixodes ticks during blood feeding. Am. J. Trop. Med. Hyg., 53(4): 397-404.

Diab, F.M. and Soliman, Z.R. (1977). An experimental study of Borrelia anserina in four species of Argas ticks. 1. Spirochete localization and densities. Z. parasitenk., 53(2):201-212.

Gaber, M.S.; Khalil, G.M.; Hoogstraal, H. and Abou-Nasr, A.E. (1984). Borrelia crocidurae localization and transmission in Ornithodoros erraticus and O. savignyi. Parasitol., 88:403-413.

Geigy, R. (1951). Transmission de Spirochaeta duttoni par Ornithodoros moubata et evolution de diverses souches de cet agent pathogene dans la souris blanche. Atti 3. Congr. Int. Ig. Med. Mediterranea. (Palermo, May 1416, 1951), pp. 1-10.

Grun, H. (1950). Die experimentelle U bertragung von Ruck follfieberspirochaten durch Ornithodoros moubata. Z. Hyg. Infekt Kank., 131 (2-3): 198-218.

Grun, H. and Blatter (1960). Zum Organotropie der Ruckfallfieberspirochate Borrelia duttoni Novy et Knapp in der Zecke Ornithodoros moubata Murrsy. Versuch einer Kennzeichung der Substanz, welche die Organotropic verursacht. Helv. Chim. Ata. 43(6): 1690-1699.

Helmy, N. (2000). Seasonal abundance of Ornithodoros (O.) savignyi and prevalence of infection with Borrelia spirochetes in Egypt. J. Egy. Soc. Parasitol., 30(2): 607-619.

Helmy, N.A.; Lotfy, N.a nd Abd ElMohsen, A. (1996). Dynamics of
Borrelia crocidurae infection in the mid gut and hemolymph of Ornithodoros (P.) erraticus and localization of the spirochete in the mid gut. Ain. Shams. Sci. Bull., 34: 405-423.

Hindle, E. (1911). The transmission of Spirochaeta duttoni. Parasitol., 4: 133-149.

Hodzic, E.; Feng, S.; Freet, K.J.; Borjesson, D.L. and Barthlod, S.W. (2002). Borrelia burgdorferi population kinetics and selected gene expression at the host vector interface. Infect. Imun., 70(7): 33823388.

Hoogstraal, H. (1985). Argasid and nuttalliellid ticks as parasites and vectors. Adv. Parasitol., 24: 135238.

Hoogstraal, H., and Kaiser, M.N. (1958). The ticks of Egypt. A brief review and key. J. Egypt. Pub. Health Assoc., 23: 51-55.

Injeyan, H.S.; Sweatman, G.K. and Matossian, R.M. (1971). Survival of Rickettsia conori in nymphal Rhipicephalus sangineus ticks at different temperatures. J. Med. Entomol., 8(4): 372-378.

Lane, R.S. and Manweiler, S.A. (1988). Borrelia coriaceae in its tick vector, Ornithodoros coriaceus (Acari: Argasidae), with emphasis on transstadial and tranovarial infection. J. Med. Entomol., 25(3): 172-177.

Markov. A.A. and Abromov, I.V. (1958). A brief summary of hemosporidian agents of farm animals and of their vectors in USSR, Vet., 35: 31-34.

Nikitina, R.E. (1964). Transovarial transmission of bird spirochetes by Argas persicus. (In Russian). Trudy 5. Konf. Prirod. Ochag. Bolez. Vop. Parazit. Respub. Sred. Azii Kazakh (September 1962), (4): 263-264.

Nikitina, R.E. (1965). On the transmission mechanism of the agent of bird spirochetosis by Argas persicus (Oken 1818) ticks. In Russian, English summary. Zool. Zh., 44(2): 294-296. In English: NAMRU3T656. 
Piesman, J.; Schneider, B.S.P. and Zeidner, N.S. (2001). Use of quantitative PCR to measure density of Borrelia burgdorferi in the mid gut and salivary glands of feeding tick vectors. J. Clin. Microbiol., 39(11): 4145-4148.

Piesman, J.; Mather, T.N.; Donahue, J.G.; Levine, J.F.; Campbell, J.D.; Karakashion, S.J. and Spielman, A.(1986). Comparative prevalence of Babesia microti and Borrelia burgdorferi in four populations of Ixodes dammini in eastern Massachusetts. Acta. Trop., 43: 263-270.

Reisinger, E.; Wendelin, I.; Gasser, R.; Halwachs, G.; Wilders-Truschnig, M.; Krejs, G. (1996). Antibiotics and increased temperature against Borrelia burgdorferi in vitro. Scand. J. Infect. Dis., 28(2):155157.

Shanbaky, N.M. and Helmy, N. (2000). First record of natural infection with Borrelia in Ornithodoros (O.) savignyi reservoir potential and specificity of the tick to Borrelia. J. Egy. Soc. Parasitol., 30(3): 765-780.

Shih, C.M.; Telford, S.R. and Spielman, A. (1995). Effect of ambient temperature on competence of deer ticks as hosts for Lyme disease spirochetes. J. Clin. Microbiol., 33(4): 958-961.

Teravsky, I.K. (1959). Concerning circulation of the agent of tick-borne relapsing fever in the organism of the vector Ornithodoros papillipes Bir. In Russian Trudy Voenno-Med. Akad. Krasnoi Armii, 105: 135-141.

Varma, M.G.R. (1956). Infections of Ornithodoros ticks, with relapsing fever spirochetes, and the mechanisms of their transmission. Ann. Trop. Med. Parasitol., 50:1831.

Varma, M.G.R. (1962). Transmission of relapsing fever spirochetes by ticks. Symp. Zool. Soc. Lond., (6): 61-82.

Young, A.S. and Leitch, B.L. (1981). Epidemiology of east coast fever: Some effects of temperature on the development of Theileria parva in the tick vector Rhipicephalus appendiculatus. Parasitol., 83: 199211.

Young, A.S.; Leitch, B.K. and Omwoyo, P.L. (1979). Induction of infective stages of Theileria parva by exposure of host ticks to high temperature. Vet. Rec., 105 (23): 531-533.

Zaher, M.A.; Soliman, Z. R. and Diab, F. M. (1977). An experimental study of Borrelia anserina in four species of Argas ticks. 2.Transstadial survival and transovarial transmission. Zeitschrift fur parasiten Kunde, 53: 213-223.

Zhenqin, Z. (1998). Borrelia burgdorferi in replete nymphal Ixodes ricinus: A localization study using light and electron microscopy. Acarologia(Paris), 39(2): 123-133.

\section{ARABIC SUMMARY}

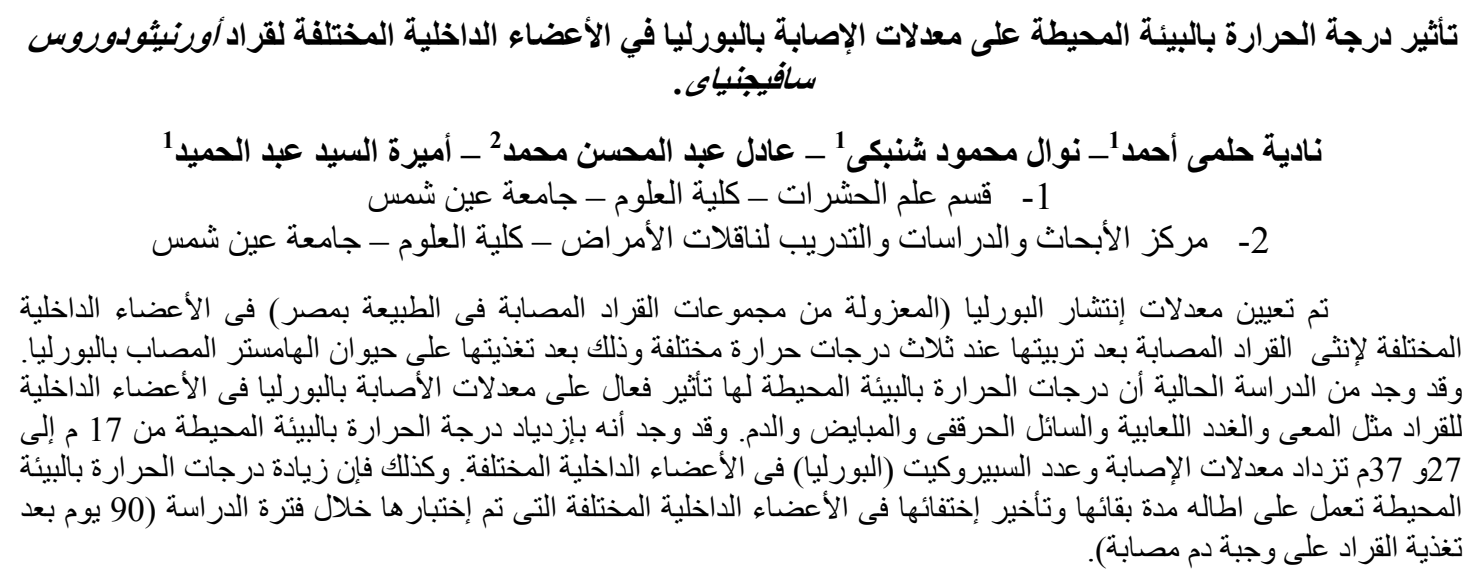

